\title{
The Effect of Contrast Agents on the Anticoagulant Properties of Oral Factor Xa Inhibitors
}

\author{
Burcu Tuncay ${ }^{1}$, Selma Arı ${ }^{1}$, Hasan Arr $^{1}$, Sencer Camcl ${ }^{1}$, Mehmet Melek ${ }^{1}$, and Tahsin \\ BOZAT $^{1}$
}

\author{
${ }^{1}$ Bursa Postgraduate Hospital
}

July 2, 2021

\begin{abstract}
Objective:The aim of this study is to evaluate the effect of iohexol as a contrast agent on the anticoagulant activity of oral factor Xa inhibitors. Methods:The study included 65 people who underwent contrast computerized tomography (CT). Patients in group 1 were using rivaroxaban (20 patients), patients in group 2 were using apixaban (20 patients), patients in group 3 were using edoxaban (20 patients), and group 4 was the control group (5 volunteers). Iohexol (60ml) was used as a contrast agent. Two tubes were used to collect $2 \mathrm{ml}$ of blood from the patients at 4 hours after the drug dose (rivaroxaban, apixaban, or edoxaban) and 1 hour after the contrast CT (CT was performed 3 hours after the drug was taken). In the control group, at any time and 1 hour after contrast CT, 2 tubes of $2 \mathrm{ml}$ of blood were collected. The anticoagulant properties of rivaroxaban, apixaban, and edoxaban were evaluated using anti-factor Xa levels. Results:The anti-factor Xa level was increased after using the contrast agent in the rivaroxaban group $(0.66 \pm 0.32 \mathrm{U} / \mathrm{ml}$ vs. $0.67 \pm 0.32 \mathrm{U} / \mathrm{ml} ; \mathrm{p}=0.01)$ and the edoxaban group $(0.74 \pm 0.35$ $\mathrm{U} / \mathrm{ml}$ vs. $0.76 \pm 0.36 \mathrm{U} / \mathrm{ml} ; \mathrm{p}=0.006)$. However, there was no significant difference in the apixaban group $(0.66 \pm 0.33 \mathrm{U} / \mathrm{ml}$ vs. $0.66 \pm 0.32 \mathrm{U} / \mathrm{ml} ; \mathrm{p}=0.21)$ and control group $(0.02 \pm 0.01 \mathrm{U} / \mathrm{ml}$ vs. $0.03 \pm 0.01 \mathrm{U} / \mathrm{ml} ; \mathrm{p}=0.33)$. Conclusion:The anticoagulant properties of rivaroxaban and edoxaban tended to increase significantly, but there was no statistically significant difference in the anticoagulant properties of apixaban with contrast agent. The increasing is too small so that these laboratory results need to validate with larger clinical trials(NCT04611386).
\end{abstract}

\section{Hosted file}

contrast factor Xa manuscript.doc available at https://authorea.com/users/423217/articles/ 528739-the-effect-of-contrast-agents-on-the-anticoagulant-properties-of-oral-factor-xainhibitors 

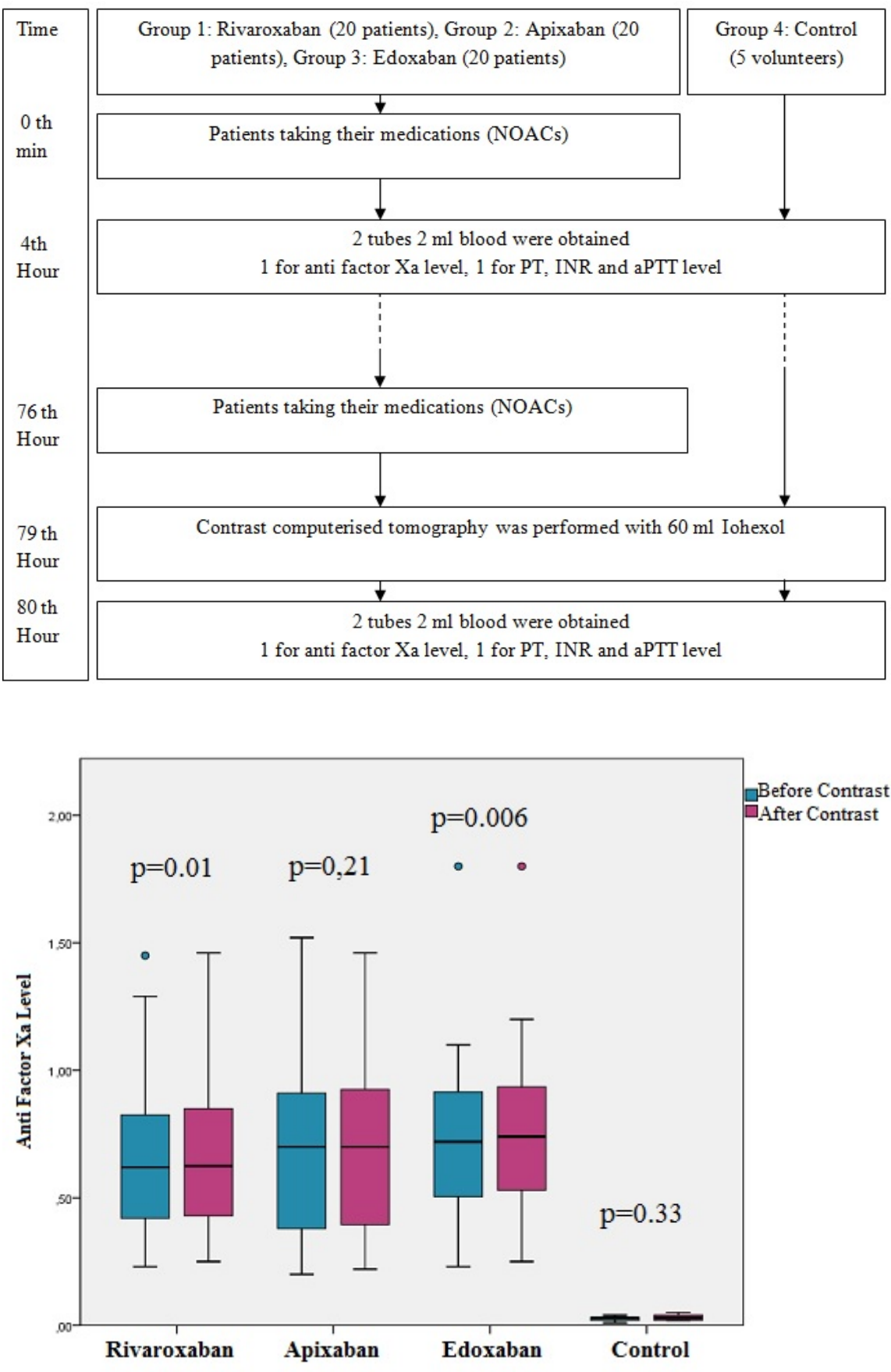